\title{
Health Coaching to Improve Hypertension Treatment in a Low-Income, Minority Population
}

\author{
David Margolius, MD \\ Thomas Bodenbeimer, MD \\ Heather Bennett, MD \\ Jennifer Wong, BA \\ Victoria Ngo, BA \\ Guillermo Padilla, BA \\ David H. Thom, MD, PbD
}

Department of Family and Community Medicine, University of California, San Francisco, California
Conflicts of interest: authors report none.

\section{CORRESPONDING AUTHOR}

Thomas Bodenheimer, MD

Department of Family and Community Medicine

University of California at San Francisco

Bldg 80-83, SF General Hospital

1001 Potrero Ave

San Francisco, CA 94110

TBodenheimer@fcm.ucsf.edu

\begin{abstract}
PURPOSE Poor blood pressure control is common in the United States. We conducted a study to determine whether health coaching with home titration of antihypertensive medications can improve blood pressure control compared with health coaching alone in a low-income, predominantly minority population.
\end{abstract}

METHODS We randomized 237 patients with poorly controlled hypertension at a primary care clinic to receive either home blood pressure monitoring, weekly health coaching, and home titration of blood pressure medications if blood pressures were elevated $(n=129)$ vs home blood pressure monitoring and health coaching but no home titration $(n=108)$. The primary outcome was change in systolic blood pressure from baseline to 6 months.

RESULTS Both the home-titration arm and the no-home-titration arm had a reduction in systolic blood pressure, with no significant difference between them. When both arms were combined and analyzed as a before-after study, there was a mean decrease in systolic blood pressure of $21.8 \mathrm{~mm} \mathrm{Hg}(P<.001)$ as well as a decrease in the number of primary care visits from 3.5 in the 6 months before the study to 2.6 during the 6 -month study period $(P<.001)$ and 2.4 in the 6 months after the study $(P<.001)$. The more coaching encounters patients had, the greater their reduction in blood pressure.

CONCLUSIONS Blood pressure control in a low-income, minority population can be improved by teaching patients to monitor their blood pressure at home and having nonprofessional health coaches assist patients, in particular, by counseling them on medication adherence. The improved blood pressure control can be achieved while reducing the time spent by physicians.

Ann Fam Med 2012;10:199-205. doi:10.1370/afm.1369.

\section{INTRODUCTION}

One-half of patients in the United States with hypertension have poorly controlled blood pressures. ${ }^{1}$ To understand why, consider usual care for hypertension. Patients are followed in 15 -minute visits that include other medical issues, and they often leave the visit without knowing their blood pressure level or goal. Physicians may not address elevated blood pressures because of competing demands, a phenomenon called clinical inertia. ${ }^{2}$

Failures in hypertension management can be attributed to 4 factors: poor patient understanding of physician instructions, lack of patient participation in decision making, low medication adherence, and clinical inertia. Fifty percent of patients leave the physician visit not understanding physician instructions ${ }^{3}$; patients rarely participate in clinical decisions ${ }^{4}$ and those who do have better outcomes ${ }^{5}$; only $36 \%$ to $39 \%$ of underserved patients adhere to antihypertensive medications ${ }^{6,7}$; and these medications are increased in only $13 \%$ of visits in which blood pressure is elevated. ${ }^{8}$ Furthermore, because $79 \%$ of hypertension visits occur in pri- 
mary care, the shrinking primary care workforce may exacerbate these shortcomings. ${ }^{9}$

Home blood pressure monitoring has been shown to improve hypertension control. ${ }^{10}$ When compared with usual care, the combination of home monitoring with home titration of antihypertensive medications is associated with better blood pressure control. ${ }^{11}$ Using nurses or pharmacists to coach patients and assist in home titration reduces blood pressure compared with usual care, ${ }^{12-18}$ but these changes involve expensive health care professionals rarely present in primary care.

The innovation described here involves a nonlicensed health team member, the health coach. Health coaches are language-concordant personnel_often medical assistants with extra training — who help patients gain the knowledge, skills, and confidence to achieve health goals. ${ }^{19}$ The combination of home monitoring with health coaching addresses the first 3 barriers above by encouraging patients to be informed, activated participants in their care. To address the fourth barrier, clinical inertia, health coaches using physician-approved protocols can assist patients in home titrating antihypertensive medications. To evaluate the feasibility and impact on blood pressure control of adding home titration to home blood pressure monitoring with health coaching by nonprofessionals, we conducted a randomized controlled trial in low-income patients with hypertension.

\section{METHODS}

\section{Overview}

We compared home blood pressure monitoring, health coaching, and home titration of antihypertensive medications (home-titration arm) with home monitoring and health coaching alone (no-home-titration arm). We did not include a usual care arm because it had already been demonstrated that home monitoring, a feature of both our study arms, improves hypertension compared with usual care. ${ }^{10}$ The primary outcome was change in systolic blood pressure (SBP) after 6 months. The study was approved by the Committee on Human Research at the University of California, San Francisco (UCSF). A detailed study protocol, published elsewhere ${ }^{20}$ is summarized here.

\section{Setting and Population}

The study was conducted between January 2009 and January 2010 in a family medicine residency clinic at a public hospital serving low-income, largely minority patients. Almost all patients are empaneled to a clinician, and the health coaches are an integral part of the clinic.

\section{Eligibility}

Patients were eligible if they had blood pressures of at least 145 systolic or at least 90 diastolic $\mathrm{mm} \mathrm{Hg}$, measured by the medical assistant at the enrollment visit and at least 1 previous visit in the last 12 months (based on chart review). Exclusion criteria were an age of younger than 30 years; not speaking English, Spanish, Cantonese, or Vietnamese; a creatinine level of greater than $1.5 \mathrm{mg} / \mathrm{dL}_{i}$ New York Heart Association class III or IV heart failure; a life expectancy of less than 1 year; or being identified by one's primary care clinician as unable to follow instructions because of physical or cognitive disability, psychiatric illness, or other reasons.

\section{Health Coaches}

The health coaches were 10 UCSF employees and volunteers with bachelor's degrees. None were physicians, midlevel practitioners, nurses, pharmacists, or other licensed clinicians. The coaches received 16 to 20 hours of training on hypertension and its medications, and on lifestyle behavior change including medication adherence counseling. The coaches, whose case loads varied from 5 to 25 patients, focused on building trusting relations with patients and counseling them on the importance of blood pressure control and medication adherence. Situated within the clinic, coaches could easily interact with clinicians by e-mail or face-to-face discussion.

\section{Enrollment and Randomization}

Patients were referred by their primary care clinicians or clinic medical assistants, or recruited by languageconcordant health coaches at their office visit. Patients interested in participating were asked if they planned to continue coming to the clinic for the next year, had a telephone, would check their blood pressure at least twice a week, and were willing to change blood pressure medicines at home if enrolled in the hometitration arm. Patients answering yes to these questions were given informed consent and enrolled. All study participants received, and were trained to use, a home blood pressure monitor (Omron HEM-711AC) and a log book to record blood pressures. Study arm assignments were randomly ordered and enclosed in sealed, consecutively numbered envelopes. After enrollment, participants were assigned to one of the study arms by opening the next sealed envelope.

\section{Intervention}

Clinicians of patients in the home-titration arm completed an algorithm of antihypertensive medication adjustments. ${ }^{20}$ Health coaches made weekly telephone calls to participants in both study arms to discuss overall well-being, adherence to action plans, and blood 
pressure values. Patients in the home-titration arm who reported blood pressure greater than $140 \mathrm{~mm} \mathrm{Hg}$ systolic or greater than $90 \mathrm{~mm} \mathrm{Hg}$ diastolic and excellent medication adherence could choose to increase their antihypertensive medication regimen according to the algorithm without a clinician appointment. In those cases, health coaches notified a physician investigator to fax the prescription to the pharmacy. Clinicians were notified of medication changes by e-mail, and health coaches entered the change in the electronic health record. The duration of the intervention was 6 months.

\section{Data Gathering}

Baseline blood pressure was the blood pressure measured and recorded in the chart by the medical assistant during the office visit at which the patient was enrolled. At 6 months, the patient was asked to come to the clinic, and blood pressure was again measured by the medical assistant using the same standard procedures as at baseline: patients were seated at the nurse station for at least 5 minutes before blood pressures were measured with an automated machine on $1 \mathrm{arm}$. Patient demographics and blood pressure medications were recorded at enrollment. For each patient encounter by telephone or in person, health coaches recorded the number of days in the past week patients reported checking their blood pressure and having missed taking a blood pressure medication, progress on existing action plans, and formulation of new action plans. Six months after study completion, patients' electronic health records were reviewed for the number of blood pressure medications at enrollment and at 6 months, and for the number of medications added and stopped during that period. Electronic records were also used to ascertain the number of primary care visits made by each patient in the 6 months before enrollment, the 6 months during the study, and the 6 months after the study.

\section{Statistical Analysis}

The primary outcome was change in SBP. Secondary outcomes included change in diastolic blood pressure, percent of patients at Joint National Committee-7 blood pressure goals $(<130 / 80 \mathrm{~mm} \mathrm{Hg}$ for diabetic patients, $<140 / 90$ $\mathrm{mm} \mathrm{Hg}$ for nondiabetic patients), and primary care visit frequency. Baseline characteristics and intervention variables (eg, number of coaching encounters, number of medication changes) were compared between study arms using a $t$ test for continuous variables and a $\chi^{2}$ test for categorical variables. Changes in systolic and diastolic pressure and in number of primary care visits were compared by study arm using a $t$ test with the standard deviation for differences computed as the sum of the squares of the standard deviations for baseline $\left(\mathrm{S}_{1}\right)$ and 6 months $\left(\mathrm{S}_{2}\right)$ divided by the square root of the sum of the $S_{1}$ and $S_{2}$ : $\mathrm{S}_{(\mathrm{s} 1-\mathrm{s} 2)}=\left(\mathrm{S}_{1}^{2}+\mathrm{S}_{2}^{2}\right) / \sqrt{ }\left(\mathrm{S}_{1}+\mathrm{S}_{2}\right)$. The change in proportion of patients at goal for blood pressure was compared by study arm using a $\chi^{2}$ test. Analyses were also conducted to look for evidence of effect modification by prespecified subgroups: starting SBP ( $\geq 160$ vs $<160 \mathrm{~mm} \mathrm{Hg}$ ), English as primary language (yes vs no), diabetes (yes vs no), sex, race/ethnicity (black vs other; Latino vs other, Asian vs other), and number of baseline medications $(0-1$ vs $\geq 2)$. In addition, we analyzed the data as for an observational study by combining both arms in order to examine predictors of change in SBP using $t$ tests for dichotomous predictor variables and analysis of variance for categorical predictor variables.

\section{RESULTS}

\section{Baseline Characteristics}

Of 241 eligible patients approached for enrollment into the study, 4 declined to participate and 237 received informed consent and enrolled. Figure 1 displays the number of patients randomized to each arm: 129 in the home-titration arm and 108 in the no-home-titration

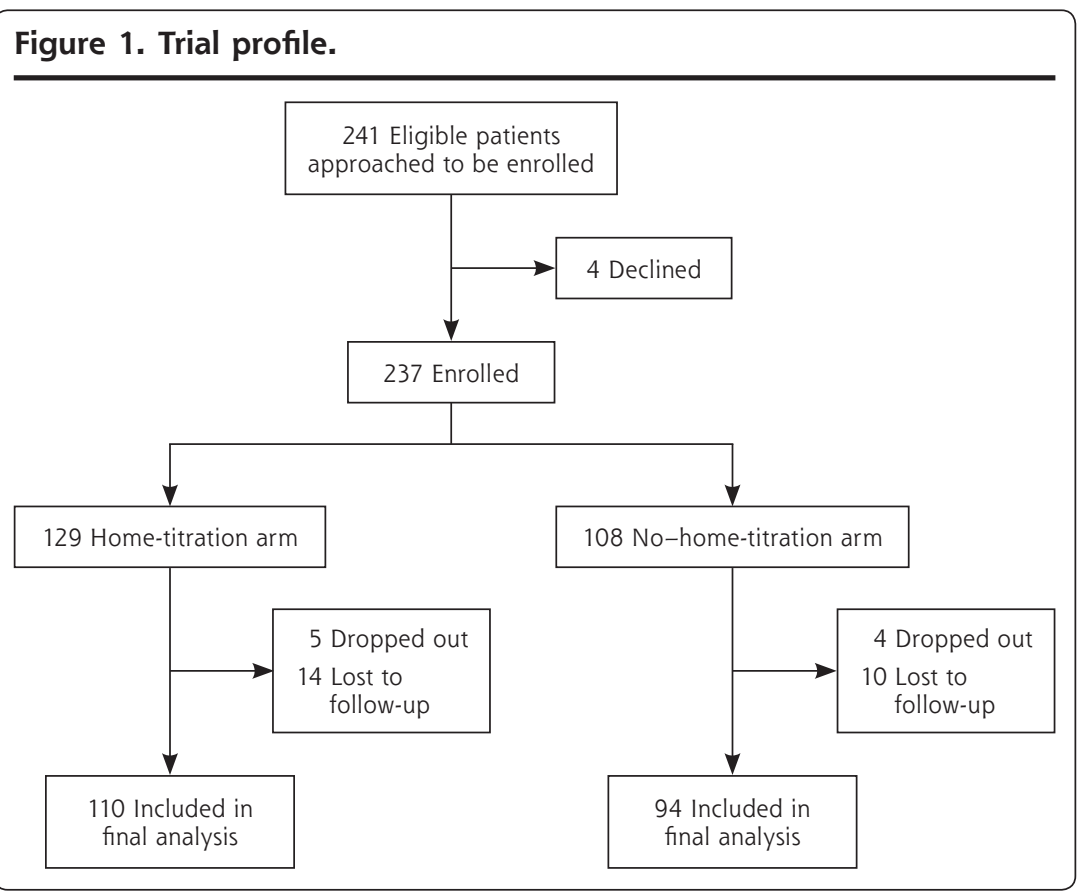


arm. Of the 237 enrolled patients, 9 dropped out and 24 were lost to follow-up, leaving 204 for analysis. There were no significant differences in attrition rates between the 2 groups. Patients who dropped out or were lost to follow-up did not differ significantly from patients who completed the study.

We found no significant differences between the 2 study arms in any of the baseline characteristics assessed (Table 1). Participants' mean age was 60 years, almost two-thirds (64\%) were women, and more than $90 \%$ were racial or ethnic minorities. Fiftytwo percent identified a primary language other than English. The mean SBP at enrollment was 160 $\mathrm{mm} \mathrm{Hg}$ for the home-titration arm and $158 \mathrm{~mm} \mathrm{Hg}$ for the nohome-titration arm.

\section{Intervention}

The 204 patients had a total of 1,932 health coach encounters. The number of encounters ranged from 0 to 27 for individual patients; 192 patients (94\%) had at least 1 encounter. Ninetytwo percent of encounters were by telephone, with the remainder taking place in person during a clinic visit. The mean number of health coach encounters per patient was 10.4 in the hometitration arm vs 10.8 in the nohome-titration arm (a nonsignificant difference). There were no significant differences between the arms in the mean number of medication changes per patient (1.5 and 1.4 , respectively).

Of the 166 medication changes among 68 patients in the home-titration arm, 135 (81\%) were made by clinicians. Only 31 medication titrations occurred at home, among 20 patients. The mean number of days in the past week on which patients reported having missed a medication dose increased slightly between the first and last coaching encounters for both arms (0.35 days in the home-titration arm and 0.33 days in the no-home-titration arm).
Table 1. Baseline Characteristics for All Participants With Blood Pressure Data at 6 Months, by Study Arm

\begin{tabular}{|c|c|c|c|}
\hline \multirow[b]{2}{*}{ Characteristic } & \multirow[b]{2}{*}{$\begin{array}{c}\text { All } \\
(\mathrm{N}=204)\end{array}$} & \multicolumn{2}{|c|}{ Study Arm } \\
\hline & & $\begin{array}{l}\text { Home Titration } \\
\quad(n=110)\end{array}$ & $\begin{array}{l}\text { No Home Titration } \\
\qquad(n=94)\end{array}$ \\
\hline Age, mean $\pm S D, y$ & $60.4 \pm 12.1$ & $60.7 \pm 12.6$ & $60.1 \pm 11.4$ \\
\hline \multicolumn{4}{|l|}{ Sex, \% } \\
\hline Women & 63.2 & 62.7 & 63.8 \\
\hline Men & 36.8 & 37.3 & 36.2 \\
\hline \multicolumn{4}{|l|}{ Race, \% } \\
\hline White non-Hispanic & 8.3 & 9.1 & 7.4 \\
\hline Black/African American & 10.8 & 10.0 & 11.7 \\
\hline Latino & 45.6 & 51.8 & 38.3 \\
\hline Asian & 34.8 & 28.2 & 42.6 \\
\hline Diabetic, \% & 33.3 & 34.5 & 31.9 \\
\hline \multicolumn{4}{|l|}{ Primary language, $\%$} \\
\hline English & 48.0 & 47.3 & 48.9 \\
\hline Spanish & 36.3 & 40.0 & 31.9 \\
\hline Cantonese & 10.3 & 8.2 & 12.8 \\
\hline Vietnamese & 5.4 & 4.5 & 6.4 \\
\hline $\mathrm{SBP}$, mean $\pm \mathrm{SD}, \mathrm{mm} \mathrm{Hg}$ & $159.3 \pm 15.3$ & $160.3 \pm 16.3$ & $158.2 \pm 14.0$ \\
\hline $\mathrm{DBP}$, mean $\pm \mathrm{SD}, \mathrm{mm} \mathrm{Hg}$ & $86.0 \pm 12.2$ & $85.1 \pm 13.3$ & $89.9 \pm 10.8$ \\
\hline Creatinine, mean $\pm S D, m g / d L$ & $0.80 \pm 0.19$ & $0.80 \pm 0.20$ & $0.80 \pm 0.18$ \\
\hline $\begin{array}{l}\text { Number of blood pressure } \\
\text { medications, mean } \pm \text { SD }\end{array}$ & $2.2 \pm 1.2$ & $2.3 \pm 1.2$ & $2.2 \pm 1.2$ \\
\hline
\end{tabular}

Table 2. Change in Blood Pressures and Number of Primary Care Office Visits in Prior 6 Months by Study Arm

\begin{tabular}{|c|c|c|c|c|c|}
\hline \multirow{2}{*}{$\begin{array}{l}\text { Measure } \\
\text { and Arm }\end{array}$} & \multicolumn{2}{|c|}{ Time Point } & \multirow[b]{2}{*}{ Change } & \multirow{2}{*}{$\begin{array}{c}\text { Differences } \\
\text { Between } \\
\text { Groups }\end{array}$} & \multirow{2}{*}{$\begin{array}{c}P \\
\text { Value }\end{array}$} \\
\hline & Baseline & 6 Months & & & \\
\hline \multicolumn{6}{|l|}{ SBP, mean, mm Hg } \\
\hline No home titration & 158.2 & 138.9 & -19.3 & & \\
\hline Home titration & 160.3 & 136.4 & -23.9 & -4.6 & NS \\
\hline \multicolumn{6}{|l|}{ DBP, mean, mm Hg } \\
\hline No home titration & 86.9 & 81.5 & -5.4 & & \\
\hline Home titration & 85.1 & 79.2 & -5.9 & -0.5 & NS \\
\hline \multicolumn{6}{|l|}{$\begin{array}{l}\text { Number of office } \\
\text { visits, mean }\end{array}$} \\
\hline No home titration & 3.53 & 2.62 & 0.91 & & \\
\hline Home titration & 3.40 & 2.49 & 0.91 & 0 & NS \\
\hline
\end{tabular}

\section{Outcomes by Study Arm}

SBP decreased by $23.9 \mathrm{~mm} \mathrm{Hg}$ in the home-titration arm and $19.3 \mathrm{~mm} \mathrm{Hg}$ in the no-home-titration arm during the 6 -month intervention period (Table 2). The difference of $4.6 \mathrm{~mm} \mathrm{Hg}$ in favor of the hometitration arm was not statistically significant. Diastolic blood pressure decreased by $5.9 \mathrm{~mm} \mathrm{Hg}$ in the hometitration arm and $5.4 \mathrm{~mm} \mathrm{Hg}$ in the no-home-titration arm, also not significant. There was no significant 
difference in the proportion of patients at their Joint National Committee-7 blood pressure goal at 6 months between the arms (47.3\% vs $43.6 \%$ ). Additionally, we found no significant difference in outcomes between arms in any of the prespecified subgroups (baseline SBP, diabetes, English speaking, sex, race/ethnicity, or number of medications at baseline). There was also no difference in the change in number of primary care office visits between arms, with participants in both arms having an average of 0.91 fewer office visits during the study period.

\section{Outcomes for Both Arms Combined}

Because only 20 patients in the home-titration arm received home titration and there was no significant difference in the change in SBP by study arm, we further analyzed the data as a nonrandomized, uncontrolled, before-after study by combining both arms (Table 3 ). For the entire group of 204 patients, all of whom had health coaching, mean SBP decreased by $21.8 \mathrm{~mm} \mathrm{Hg}$ between baseline and 6 months $(P<.001)$. The mean number of primary care office visits decreased from 3.46 in the 6 months before the start of coaching to 2.55 during the 6 months of coaching in both arms combined $(P<.001)$. The mean number of visits in the 6 months after the end of the intervention period was 2.38 .

\section{Predictors of Change in Blood Pressure for Both Arms Combined}

We also analyzed our combined data as observational study data to investigate the association between baseline and process variables and change in SBP (Table 4). Higher SBP at baseline was significantly associated with larger reductions in SBP both when dichotomized at less than 160 or greater than or equal to $160 \mathrm{~mm}$ $\mathrm{Hg}(P<.001)$ and when kept as a continuous variable (Pearson correlation coefficient $=-0.50, P<.001)$. No significant associations were found for other subgroups with other baseline characteristics. There was a significant positive association for number of health coach

Table 3. Change in Blood Pressures and Number of Primary Care Office Visits in Prior 6 Months Combining Both Study Arms ( $=204)$

\begin{tabular}{|c|c|c|c|c|}
\hline \multirow[b]{2}{*}{ Measure } & \multicolumn{2}{|c|}{ Time Point } & \multirow[b]{2}{*}{ Change } & \multirow{2}{*}{$\begin{array}{c}P \\
\text { Value }\end{array}$} \\
\hline & Baseline & 6 Months & & \\
\hline SBP, mean, mm Hg & 159.3 & 137.5 & -21.8 & $<.001$ \\
\hline DBP, mean, mm Hg & 86.0 & 80.3 & -5.7 & $<.001$ \\
\hline $\begin{array}{l}\text { Number of office } \\
\text { visits, mean }\end{array}$ & 3.46 & 2.55 & -0.91 & $<.001$ \\
\hline \multicolumn{5}{|c|}{$\mathrm{DBP}=$ diastolic blood pressure; $\mathrm{SBP}=$ systolic blood pressure. } \\
\hline \multicolumn{5}{|c|}{ Note: Data were analyzed as for a before-after study. } \\
\hline
\end{tabular}

encounters, trichotomized into 3 approximately equal groups, and SBP reduction. Number of changes of antihypertensive medications - either by clinician titration or home titration - was not associated with change in SBP, but there was a trend for an increase in the number of medications and reduction in $\operatorname{SBP}(P=.065)$. The change in the number of missed medication days between the first and last coaching encounters was not significantly associated with change in SBP. In multivariate analysis, the number of coaching encounters remained significantly associated with reduction in SBP after controlling for baseline SBP and change in number of medications $(P=.03)$.

\section{DISCUSSION}

In this trial comparing health coaching with vs without home titration, both arms had nearly identical, clinically meaningful SBP reductions. The feasibility of home titration remains uncertain, as less than one-fifth of patients in that arm actually undertook an adjustment of their antihypertensive medication at home.

When data were analyzed as before-after study data with both arms combined, patients experienced a mean SBP decrease of nearly $22 \mathrm{~mm} \mathrm{Hg}$. Although there was no control group, this magnitude is greater than the SBP reductions in control groups of 7 other studies using health coaching, which ranged from 2 to $14 \mathrm{~mm} \mathrm{Hg} .{ }^{12-18}$ Patients had an average of 0.9 fewer primary care office visits in the 6-month study period compared with the 6 months before the study, and this difference was maintained in the 6 months after the study.

Our findings support 3 take-home points for improving blood pressure treatment in primary care. First, the more health coach encounters patients had, the greater their reduction in SBP, suggesting that increasing doses of health coaching are associated with lower blood pressures. Likely, health coaching works through improving patients' diet, exercise, medication adherence, and overall engagement with their disease.

Second, blood pressure control was achieved without added physician time; in fact, the number of physician visits for study patients dropped in the 6 months during and after the intervention. With these interventions, blood pressure can thus be improved without increasing demand on physician time.

Third, nonprofessional caregivers can contribute importantly to hypertension management. Unlicensed health care workers with relatively minimal training can coach patients with hypertension, focusing on medication adherence. Seven recent trials involving health coaching depended on health professionals 
generally having higher salaries, specifically pharmacists $^{12,13,15,18}$ and registered nurses..$^{14,16,17}$ The SBP reductions found in our study are similar to those found in the coaching arm of those trials, which ranged from 13 to $28 \mathrm{~mm} \mathrm{Hg}$. Participants in the 2 studies with coaching-group SBP reductions greater than $20 \mathrm{~mm}$ $\mathrm{Hg}$ had higher socioeconomic levels than our study participants. ${ }^{12,17}$ In our study, primary care clinicians were enthusiastic about the participation of health coaches. ${ }^{21}$ The clinical outcomes achieved suggest that redesigning primary care for hypertension care does not require high-cost professionals.

This study had several limitations. A usual-care arm would have been helpful to further substantiate the

\section{Table 4. Association Between Baseline Patient Characteristics, Process Variables, and Change in SBP for All Participants}

\begin{tabular}{|c|c|c|c|c|}
\hline \multirow[b]{2}{*}{ Measure } & \multicolumn{2}{|c|}{ Mean SBP } & \multirow[b]{2}{*}{ Change } & \multirow{2}{*}{$\begin{array}{c}P \\
\text { Value }\end{array}$} \\
\hline & Baseline & 6 Months & & \\
\hline \multicolumn{5}{|l|}{ Diabetes } \\
\hline Yes $(n=68)$ & 161.0 & 139.5 & -21.5 & \\
\hline No $(n=136$ & 158.5 & 136.5 & -22.0 & NS \\
\hline \multicolumn{5}{|l|}{ English speaking } \\
\hline Yes $(n=98)$ & 160.9 & 140.0 & -20.9 & \\
\hline No $(n=106)$ & 157.9 & 135.2 & -22.7 & NS \\
\hline \multicolumn{5}{|l|}{ Black } \\
\hline Yes $(n=22)$ & 159.2 & 137.3 & -21.9 & \\
\hline No $(n=182)$ & 160.4 & 139.6 & -20.8 & NS \\
\hline \multicolumn{5}{|l|}{ Latino } \\
\hline Yes $(n=93)$ & 161.0 & 140.0 & -21.0 & \\
\hline No $(n=111)$ & 157.4 & 134.6 & -22.7 & NS \\
\hline \multicolumn{5}{|l|}{ Sex } \\
\hline Female $(n=129)$ & 158.6 & 136.4 & -22.2 & \\
\hline Male $(n=75)$ & 160.6 & 139.4 & -21.2 & NS \\
\hline \multicolumn{5}{|l|}{ SBP at baseline } \\
\hline$\geq 160 \mathrm{~mm} \mathrm{Hg}(\mathrm{n}=77)$ & 174.6 & 143.7 & -30.9 & \\
\hline$<160 \mathrm{~mm} \mathrm{Hg}(\mathrm{n}=127)$ & 150.1 & 133.8 & -16.3 & $<.001$ \\
\hline \multicolumn{5}{|l|}{$\begin{array}{l}\text { Number of blood pressure } \\
\text { medications at baseline }\end{array}$} \\
\hline 0 or $1(n=55)$ & 153.2 & 134.4 & -18.8 & \\
\hline $2(n=75)$ & 160.9 & 136.6 & -24.4 & \\
\hline$\geq 3(n=74)$ & 162.3 & 140.9 & -21.5 & NS \\
\hline \multicolumn{5}{|l|}{ Number of coaching encounters } \\
\hline $1-5(n=62)$ & 157.8 & 140.6 & -17.2 & \\
\hline $6-12(n=68)$ & 158.8 & 137.2 & -21.6 & \\
\hline$>12(n=74)$ & 161.1 & 135.2 & -25.9 & .008 \\
\hline \multicolumn{5}{|l|}{ Number of medication changes } \\
\hline $0(n=83)$ & 156.5 & 136.2 & -20.3 & \\
\hline $1(n=50)$ & 159.4 & 137.4 & -22.0 & \\
\hline$\geq 2(n=71)$ & 162.6 & 139.1 & -23.5 & NS \\
\hline \multicolumn{5}{|c|}{$\begin{array}{l}\text { Change in number of medications } \\
\text { from baseline to } 6 \text { months }\end{array}$} \\
\hline Fewer medications $(n=27)$ & 160.4 & 145.0 & -15.3 & \\
\hline No change $(n=136)$ & 157.9 & 135.6 & -22.3 & \\
\hline More medications $(n=41)$ & 163.5 & 138.9 & -24.6 & .065 \\
\hline \multicolumn{5}{|c|}{$\begin{array}{l}\text { Change in number of days missed } \\
\text { blood pressure medication from } \\
\text { baseline to } 6 \text { months }\end{array}$} \\
\hline Fewer missed days $(n=21)$ & 159.5 & 141.6 & -18.0 & \\
\hline No change $(n=119)$ & 159.4 & 137.2 & -22.2 & \\
\hline More missed days $(n=27)$ & 161.3 & 136.7 & -24.7 & NS \\
\hline
\end{tabular}

improvement in SBP found in both intervention arms. In recent studies involving patients with elevated baseline SBP levels, however, levels dropped by $2,6,7,10,12$, and 14 $\mathrm{mm} \mathrm{Hg}$ with usual care, reductions considerably smaller than the approximately $20-\mathrm{mm} \mathrm{Hg}$ SBP reduction in both groups of our study. ${ }^{11-18}$

In an effort to pattern our study intervention to standard clinical care, we used blood pressures measured by medical assistants at the office visit. This approach may have introduced more random error creating a bias toward not finding a difference between study arms. It is unlikely that it affected the result to the point of masking a true significant difference, however. The potential impact on the before-after analysis would be toward the null hypothesis, making our results a conservative estimate of actual change from baseline to 6 months.

The association between number of coaching encounters and SBP reduction, while supportive of a true effect of health coaching, relied on observational data and could reflect confounding by unmeasured variables.

Although we expected health coaching to improve medication adherence, self-reported adherence decreased over the course of the study. Two factors may explain this seemingly paradoxic finding. First, on the basis of coaches' reports, many patients at baseline did not know their medications well enough to accurately report adherence. Second, patients may have become more truthful as they developed trusting relationships with their coaches. Also, self-reported adherence correlates poorly with more objective adherence measures.

Evidence is accumulating that team-based interventions can improve 
hypertension control. The results of our trial suggest that delegating hypertension care to nonprofessional staff trained as health coaches, giving each patient a home blood pressure monitor, and creating hometitration medication algorithms are innovations that can improve care while saving physician time.

To read or post commentaries in response to this article, see it online at http://www.annfammed.org/content/10/3/199.

Key words: hypertension; primary care; health coaching; medication adherence; medication therapy management; practice-based research

Submitted June 24, 2011; submitted, revised, September 24, 2011; accepted October 24, 2011.

Funding support: This work was funded by the Kaiser Permanente Community Benefit Program.

Previous presentation: The findings were presented in part at the UCSF Department of Family and Community Medicine colloquium in San Francisco in May 2011.

Acknowledgments: We wish to thank Omron Healthcare for contributing home blood pressure monitors for this study.

\section{References}

1. Egan BM, Zhao Y, Axon RN. US trends in prevalence, awareness, treatment, and control of hypertension, 1988-2008. JAMA. 2010; 303(20):2043-2050.

2. Parchman ML, Pugh JA, Romero RL, Bowers KW. Competing demands or clinical inertia: the case of elevated glycosylated hemoglobin. Ann Fam Med. 2007;5(3):196-201.

3. Schillinger D, Piette J, Grumbach K, et al. Closing the loop: physician communication with diabetic patients who have low health literacy. Arch Intern Med. 2003;163(1):83-90.

4. Braddock CH III, Edwards KA, Hasenberg NM, Laidley TL, Levinson W. Informed decision making in outpatient practice: time to get back to basics. JAMA. 1999;282(24):2313-2320.

5. Bodenheimer T. A 63-year-old man with multiple cardiovascular risk factors and poor adherence to treatment plans. JAMA. 2007;298 (17):2048-2055.

6. Bailey JE, Wan JY, Tang J, Ghani MA, Cushman WC. Antihypertensive medication adherence, ambulatory visits, and risk of stroke and death. J Gen Intern Med. 2010;25(6):495-503.

7. Hyre AD, Krousel-Wood MA, Muntner P, Kawasaki L, DeSalvo KB. Prevalence and predictors of poor antihypertensive medication adherence in an urban health clinic setting. J Clin Hypertens (Greenwich). 2007;9(3):179-186.
8. Okonofua EC, Simpson KN, Jesri A, Rehman SU, Durkalski VL, Egan $\mathrm{BM}$. Therapeutic inertia is an impediment to achieving the Healthy People 2010 blood pressure control goals. Hypertension. 2006; 47(3):345-351.

9. Margolius $D$, Bodenheimer T. Controlling hypertension requires a new primary care model. Am J Manag Care. 2010;16(9):648-650.

10. Agarwal R, Bills JE, Hecht TJ, Light RP. Role of home blood pressure monitoring in overcoming therapeutic inertia and improving hypertension control: a systematic review and meta-analysis. Hypertension. 2011;57(1):29-38.

11. McManus RJ, Mant J, Bray EP, et al. Telemonitoring and self-management in the control of hypertension (TASMINH2): a randomised controlled trial. Lancet. 2010;376(9736):163-172.

12. Green BB, Cook AJ, Ralston JD, et al. Effectiveness of home blood pressure monitoring, Web communication, and pharmacist care on hypertension control: a randomized controlled trial. JAMA. 2008:299(24):2857-2867.

13. Magid DJ, Ho PM, Olson KL, et al. A multimodal blood pressure control intervention in 3 healthcare systems. Am J Manag Care. 2011;17(4):e96-e103.

14. Rudd P, Miller NH, Kaufman J, et al. Nurse management for hypertension. A systems approach. Am J Hypertens. 2004;17(10):921-927.

15. Mehos BM, Saseen JJ, MacLaughlin EJ. Effect of pharmacist intervention and initiation of home blood pressure monitoring in patients with uncontrolled hypertension. Pharmacotherapy. 2000; 20(11):1384-1389.

16. Bosworth HB, Powers BJ, Olsen MK, et al. Home blood pressure management and improved blood pressure control: results from a randomized controlled trial. Arch Intern Med. 2011;171(13): 1173-1180.

17. Hacihasanoğlu R, Gözüm S. The effect of patient education and home monitoring on medication compliance, hypertension management, healthy lifestyle behaviours and BMI in a primary health care setting. J Clin Nurs. 2011;20(5-6):692-705.

18. Weber CA, Ernst ME, Sezate GS, Zheng S, Carter BL. Pharmacistphysician comanagement of hypertension and reduction in 24-hour ambulatory blood pressures. Arch Intern Med. 2010;170(18): 1634-1639.

19. Bennett HD, Coleman EA, Parry C, Bodenheimer T, Chen EH. Health coaching for patients with chronic illness. Fam Pract Manag. 2010;17(5):24-29.

20. Bennett $H$, Laird K, Margolius D, Ngo V, Thom DH, Bodenheimer $T$. The effectiveness of health coaching, home blood pressure monitoring, and home-titration in controlling hypertension among lowincome patients: protocol for a randomized controlled trial. BMC Public Health. 2009;9:456-461.

21. Margolius D, Wong J, Goldman ML, Rouse-Iniguez J, Bodenheimer T. Delegating responsibility from clinicians to nonprofessional personnel: the example of hypertension control. J Am Board Fam Med. 2012;25(2):209-215. 